\title{
Socioeconomic context in area of living and risk of myocardial infarction: results from Stockholm Heart Epidemiology Program (SHEEP)
}

\author{
M Kölegård Stjärne, F Diderichsen, C Reuterwall, J Hallqvist for the Sheep Study \\ Group
}

J Epidemiol Community Health 2002;56:29-35

\begin{abstract}
Study objective: To analyse if socioeconomic characteristics in area of living affect the risk of myocardial infarction in a Swedish urban population, and to evaluate to what extent the contextual effect is confounded by the individual exposures.

Design: A population based case-referent study (SHEEP).

Setting: Cases ( $n=1631$ ) were all incident first events of myocardial infarction during 1992-1994. The study base included all Swedish citizens aged 45-70 years, living in Stockholm metropolitan area during these years. The social context of all metropolitan parishes $(n=89)$ was determined by routine statistics on 21 socioeconomic indicators. A factor analysis of the socioeconomic indicators resulted in three dimensions of socioeconomic deprivation, which were analysed separately as three different contextual exposures.

Main results: The main characteristics of the extracted factors were; class structure, social exclusion and poverty. Among men, there were increased relative risks of similar magnitudes (1.28 to 1.33) in the more deprived areas according to all three dimensions of the socioeconomic context. However, when adjusting for individual exposures, the poverty factor had the strongest contextual impact. The contextual effects among women showed a different pattern. In comparison with women living the most affluent areas according to the class structure index, women in the rest of Stockholm metropolitan area had nearly $70 \%$ higher risk of myocardial infarction after adjustment for individual social exposures. Conclusions: The results suggest that the socioeconomic context in area of living increases the risk of myocardial infarction. The increased risk in only partially explained by individual social factors (the compositional effect).
\end{abstract}

See end of article for authors' affiliations

Correspondence to:

Correspondence to:
Maria Kölegård Stjärne, Karolinska Institutet,

Department of Public

Health Sciences, Division

of Social Medicine, SE-171

76 Stockholm, Sweden:

maria.k.stjarne@phs.ki.se

Accepted for publication 13 June 2001
A n increasing number of studies analyse the health impact of the social context on local and national level. Since 1996 more than 20 scientific papers on individual health effects of socioeconomical contextual exposures have been published. $^{1-22}$

Haan et al were among the first to conduct a study on contextual effects in small areas on mortality with control for individual characteristics. They reported that residents in a poverty area had a relative risk of 1.50 for all cause mortality over a nine year period, after adjustment for individual confounders including individual income. ${ }^{23}$ More recently Anderson et al also showed an increased risk of all cause mortality in the US for inhabitants in census tract areas with a low median income after adjustment for family income. ${ }^{1}$ Other American and British studies have confirmed the relation between contextual characteristics on the small area level on both all cause and cardiovascular mortality. ${ }^{23} 1213152122$ Some studies have reported less favourable profiles of cardiovascular risk factors and increased prevalence of coronary heart disease in socioeconomically deprived areas. ${ }^{7812}{ }^{19}$ Contextual effects on other outcomes like long term illness have also been published, ${ }^{416} 17$ and recently Yen and Kaplan reported results from Alameda county showing an excess risk of developing depressive symptoms and worse perceived health status for poverty area residents. ${ }^{20}$

The social context should be understood as the political, cultural, social and economic environment, which characterise a society. Area deprivation is a concept often used when studying contextual aspects operating at the level of the local community. It is claimed that it "may summarise an area's potential for health risk from ecological exposures such as from the concentration of poverty, unemployment, economic disinvestment, and social disorganisation". ${ }^{1}$ Income distribution is another aspect of the social context. Associations between income inequality and mortality have been described in international comparison ${ }^{24}$ and within the United States. ${ }^{15}{ }^{25-27}$ One hypothesis of the mechanisms behind this is that psychosocial factors-that is, perceived inequalities mediates the relation ${ }^{28}$ - but it has been argued that these results are equally compatible with a mechanism where the actual material conditions of the relatively deprived have aetiological implications. ${ }^{29}$ It is shown in the US, that wide income disparities coexist with disinvestment in public infrastructure like education, higher rates of unemployment, welfare dependency and medically uninsured, as well as more homicides and violent crimes. ${ }^{25}$ Many of these material conditions are expressed in local communities, offering a link between the analyses of deprivation effects in small areas and income inequality in larger communities.

Recent research has pointed at the need for more focused attention to the meaning of neighbourhood quality and to the development of measures of these aspects. ${ }^{21}$ A variety of indices and different methods have been developed to measure the social and material resources in the area. ${ }^{24213031}$ Also single variables such as median income ${ }^{13}$ and number of female headed households, ${ }^{7}$ etc, have been used as indicators for the same purpose. Many of the indices have primarily been developed to identify health care needs in areas for resource allocation purposes, ${ }^{32-34}$ but have anyway been applied in aetiological studies.22

The aim of this study was to analyse the contextual effect of social deprivation on risk of myocardial infarction among men 
and women separately, considering possible confounding from the corresponding individual social factors (the compositional effect). Another aim was to develop an index identifying and measuring specific socioeconomic contexts of parishes in the Stockholm metropolitan area.

\section{METHOD}

SHEEP is a population based case-referent study of causes of myocardial infarction. ${ }^{36}{ }^{37}$ The study base included all Swedish citizens 45-70 years old who had not experienced myocardial infarction before and who were living in the Stockholm county. The cases were all first events of myocardial infarction that occurred in the studybase during 1992 to 1994 . Non-fatal cases were identified through a special organisation at the 10 emergency hospitals. By screening of hospital discharge register missed cases were found. Fatal cases were identified from death certificates. All hospitalised cases were diagnosed according to standardised criteria using information on symptoms, ECG and enzymes. ${ }^{38}$ Cases were included at the time of disease incidence. Simultaneously one referent per case was randomly selected from the study base after stratification for age, sex and hospital catchment area. More referents than cases were finally included, because sometimes the referent was already included when the case chose not to participate. In addition, if a referent at first did not to participate another one was sampled, but sometimes they both ended up participating.

To fully explore the contextual exposure contrast in the whole region we did not want to adjust for hospital catchment area. As hospital catchment area is correlated with parish area characteristics the stratified sampling of referents would introduce confounding, biasing the relative risks towards unity. The sampling effect was corrected by giving the referents in each hospital catchment area weights, according to the proportion of person years in the study base. We did this separately in each age and sex stratum.

In total the SHEEP study included 2246 cases and 3206 controls. The questionnaire response rate among cases was $72 \%$ for women and $81 \%$ for men, while corresponding figures among controls were $70 \%$ and $75 \%$. The subjects responded to the same extent in different age groups and were equally inclined to participate from the different catchment areas. Stockholm county comprises 143 parishes, 89 metropolitan and 54 rural (defined by the number of block buildings in the area). Cases (61) and referents (82) who were living in the rural parishes were excluded because rural living modifies the effect of socioeconomic deprivation. The process of economic segregation is also strongest in the metropolitan areas. ${ }^{15}$ Cases (59) and referents (60), who lacked address information the year before inclusion or who had moved to the county during the year before inclusion were also excluded from the analyses. In the final study sample 3804 people were included, 513 female and 1118 male cases, 730 female and 1443 male referents.

\section{Exposure information}

Individual exposure information and residence history were collected by a postal questionnaire and in case of missing answers a supplementary telephone interview was done. For fatal cases the questionnaire was answered by a close relative 6 to 12 month later.

Parish of living was chosen as the geographical unit of the social context. In 1990 the populations ranged from 816 to 56478 in the 89 metropolitan parishes and the median population was 14422 .

To determine the socioeconomic context in Stockholm metropolitan area we used a wide range of socioeconomic indicators that cover social, economic and demographic aspects (see table 1). The ecological data were derived from the Office of Research and Statistics in Stockholm (USK). This kind of indicator has previously been used in different constructions of measurement scales of social environment and deprivation 24213031 and measures important aspects of socioeconomic status and population structure in each area of living.

As residential areas in the Stockholm metropolitan region have been formed and repopulated in different historical contexts there might be more than one dimension of social deprivation. Therefore we performed an exploratory factor analysis

Table 1 Definitions of the 21 socioeconomic indicators used in the factor analysis together with mean value and range, calculated for each of the 89 metropolitan parishes in Stockholm

\begin{tabular}{|c|c|c|c|c|}
\hline Indicator & & $\begin{array}{l}\text { Mean } \\
(\%)\end{array}$ & $\begin{array}{l}\text { Minimum } \\
(\%)\end{array}$ & $\begin{array}{l}\text { Maximum } \\
(\%)\end{array}$ \\
\hline Low education $25-44$ years & $\begin{array}{l}\text { Proportion with no more than nine year compulsory school and upper } \\
\text { secondary school in the age gr. of } 25 \text { to } 44 \text {. }\end{array}$ & 60.14 & 34.50 & 83.43 \\
\hline Low education $45-64$ years & $\begin{array}{l}\text { Proportion with no more than nine year compulsory school or elementary } \\
\text { school in the age gr. of } 45 \text { to } 64 \text {. }\end{array}$ & 41.50 & 18.32 & 73.97 \\
\hline Blue collar & Proportion manual workers. & 37.83 & 14.48 & 68.37 \\
\hline White collar & Proportion non-manual employees. & 37.72 & 14.26 & 58.87 \\
\hline Low income men $20-64$ years & $\begin{array}{l}\text { Proportion men } 20 \text { to } 64 \text { years of age, included in the lowest county } \\
\text { income quintile. }\end{array}$ & 18.41 & 7.59 & 30.77 \\
\hline High income men $20-64$ years & $\begin{array}{l}\text { Proportion men } 20 \text { to } 64 \text { years of age, included in the highest county } \\
\text { income quintile. }\end{array}$ & 18.66 & 3.60 & 44.98 \\
\hline Unemployment $18-24$ years & Proportion Unemployed in the age gr. of 18 to 24 . & 4.68 & 0.00 & 10.34 \\
\hline Unemployment $25-64$ years & Proportion Unemployed in the age gr. of 25 to 64 . & 1.84 & 0.50 & 3.88 \\
\hline Not gainfully employed $25-44$ years & Proportion not gainfully employed in the age gr. of 25 to 44 . & 17.46 & 9.02 & 35.06 \\
\hline Not gainfully employed $45-64$ years & Proportion not gainfully employed in the age gr. of 45 to 64 . & 18.09 & 5.26 & 31.98 \\
\hline Lone parents & $\begin{array}{l}\text { Proportion single parents with children below } 18 \text { years in the age gr. of } \\
25 \text { to } 44 \text {. }\end{array}$ & 5.72 & 3.16 & 9.47 \\
\hline Living alone $45-64$ years & Proportion people living alone in the age gr. of 45 to 65 . & 21.16 & 5.62 & 49.30 \\
\hline Living alone 65 years + & Proportion people living alone in the age gr. of 65 years and older. & 40.66 & 22.01 & 60.53 \\
\hline Immigrants, European & Proportion European emigrants and Swedes born in Europe. & 8.80 & 3.58 & 31.77 \\
\hline Immigrants, non European & Proportion non European immigrants and Swedes born outside of Europe. & 8.42 & 1.05 & 49.35 \\
\hline Social welfare & $\begin{array}{l}\text { Proportion people, older than } 18 \text {, which received social welfare sometime } \\
\text { during one year. }\end{array}$ & 5.15 & 0.67 & 16.72 \\
\hline Moved from & Proportion people moved from an address. & 12.84 & 6.90 & 18.63 \\
\hline Moved to & Proportion people moved to an address. & 13.24 & 7.01 & 28.13 \\
\hline Public utility & Proportion public housing. & 26.39 & 0.00 & 63.45 \\
\hline Owner occupied & Proportion Owner occupied housing (apartments and detached houses). & 52.50 & 12.76 & 96.05 \\
\hline Number of nationalities & The number of countries represented by more then five persons. & 51 & 3 & 103 \\
\hline
\end{tabular}


to determine dimensions in our data of socioeconomic context. Three factors were derived from the analysis, and one index was created from each factor. We used five exposure levels throughout the analysis, as we wanted information on the exposure-response relation; would there be monotonous gradients or thresholds? We also report relative risks based on dichotomised contextual exposures. These exposure categories were not formed according to any a priori theory of cut offs.

Socioeconomic status (SES) was operationalised by socioeconomic group based on occupations according to a classification system developed by Statistics Sweden. ${ }^{39}$ We used information on each subject's latest occupation before inclusion in SHEEP and the following four categories were formed to control for confounding: (1) unskilled and skilled manual workers, (2) low level non-manual employees, (3) self employed, and (4) medium and high level non-manual employees.

Information from the questionnaire on each participant's highest educational level was grouped in three categories: (1) compulsory school and vocational training, (2) upper secondary school, and (3) university.

Information on employment status at inclusion was categorised as (1) employed and self employed, (2) old age pensioners, (3) unemployed, students and housewives, and (4) long term ill and early retirement pensioners.

Marital status was constructed as a dichotomy between participants who were either married or cohabiting and those who were not.

We used information on country of birth to control for ethnicity and made a dichotomy between participants born in Sweden and those born abroad.

\section{Statistical analyses}

For the contextual measure we used the prevalence of 21 social, economic and demographic indicators of the context in all parishes $(n=89)$, and performed an exploratory factor analysis (maximum likelihood) using oblique rotation (with a solution based on oblimin criterion with kaiser normalisation). A three factor model was derived and by using the regression method one index for each factor was constructed (F). The predicted scores for each parish was given by:

$$
\mathrm{F}=\mathrm{XR}^{-1} \mathrm{~B} \text {, }
$$

where $\mathrm{X}$ is a vector of the indicators $(1 \times 21)$; $\mathrm{R}$ is the correlation matrix for the indicators $(21 \times 21)$; and $\mathrm{B}$ is the matrix of factor loadings $(21 \times 3) .^{40}$ The contextual exposures were divided into quintiles based on cut off points derived from the distribution of parishes.

The model strategy was to fit multilevel logistic regression models regarding parishes as second level units. In case the variance at the second level was negligible, a single level regression model was fitted instead. Four dummy variables accounted for the five exposure levels originating from the factor analysis. Under the multilevel model these are variables at the parish level whereas under the single level model they are assigned to individuals.

The sampling of referents was stratified by age, gender and hospital catchment area. All analyses were adjusted by age in five year age groups and stratified by gender to allow for gender differences in the relation. Furthermore, all models included referent weights to abolish the effect of stratified sampling according to hospital catchment area. Odds ratios as estimators of relative risk and 95\% confidence intervals were computed using unconditional logistic regression as cases and referents were not regarded as individually matched and unconditional logistic regression allows the use of information from all available referents in SHEEP. To distinguish the contextual effect from the compositional we included individual covariates that operate in the segregation process (that is, socioeconomic status, educational level, employment status, marital status and country of birth) in the regression model.

All statistical analyses were carried out by SAS version 6.12, MlwiN version 1.1 and SPSS version 7.5.

\section{RESULTS}

\section{Measuring social context}

The factor analysis of the 21 variables and 89 areas resulted in three factors. The pattern matrix is shown in table 2 by figures in bold type. Together the three factors explain $76 \%$ of the common variance in the data. Our assumption was that correlation between factors could occur, and therefore we used an oblique rotation. The obtained correlations among factors were: -0.163 for factor 1 and 2, 0.296 for factor 1 and 3, 0.344 for factor 2 and 3 . The same three factors appeared when applying other methods of factor analysis or principal component analysis.

Our interpretation was that:

Table 2 Pattern matrix from the factor analysis with factor loadings (loadings $\geqslant 0.5$ marked) for each socioeconomic indicator

\begin{tabular}{llll}
\hline & Factor 1 & Factor 2 & Factor 3 \\
\hline Low education 45-64 years & $\mathbf{0 . 9 9}$ & 0.04 & -0.07 \\
High income men 20-64 years & -0.95 & -0.46 & 0.07 \\
White collar & -0.94 & 0.11 & -0.10 \\
Blue collar & $\mathbf{0 . 9 1}$ & -0.13 & 0.13 \\
Low education 25-44 years & $\mathbf{0 . 8 5}$ & -0.35 & 0.03 \\
Unemployment 18-24 years & $\mathbf{0 . 5 9}$ & -0.10 & 0.13 \\
Living alone 45-64 years & -0.06 & $\mathbf{0 . 9 7}$ & -0.14 \\
Living alone 65 years + & -0.11 & $\mathbf{0 . 8 9}$ & -0.12 \\
Moved to & -0.05 & $\mathbf{0 . 7 4}$ & -0.10 \\
Owner occupied & 0.10 & -0.72 & -0.28 \\
Low income men 20-64 years & 0.17 & $\mathbf{0 . 6 9}$ & 0.24 \\
Moved from & -0.10 & $\mathbf{0 . 6 8}$ & 0.19 \\
Not gainfully employed 45-64 years & 0.19 & $\mathbf{0 . 6 6}$ & 0.38 \\
Unemployment 25-64 years & 0.24 & $\mathbf{0 . 6 5}$ & 0.36 \\
Immigrants, non European & -0.06 & -0.03 & $\mathbf{0 . 8 6}$ \\
Social welfare & 0.24 & 0.17 & $\mathbf{0 . 7 5}$ \\
Not gainfully employed 25-44 years & -0.17 & 0.34 & $\mathbf{0 . 7 4}$ \\
Public housing & 0.21 & 0.03 & $\mathbf{0 . 6 8}$ \\
Lone parents & 0.16 & 0.05 & $\mathbf{0 . 6 3}$ \\
Number of nationalities & -0.33 & 0.17 & $\mathbf{0 . 5 7}$ \\
Immigrants, European & 0.18 & -0.20 & $\mathbf{0 . 5 0}$ \\
\hline
\end{tabular}


Table 3 Relative risks (95\% confidence intervals) of myocardial infarction by exposure quintile for the class structure index

\begin{tabular}{|c|c|c|c|c|c|}
\hline \multirow[b]{2}{*}{ Model } & \multicolumn{5}{|c|}{ Exposure quintile } \\
\hline & 1 & 2 & 3 & 4 & 5 \\
\hline \multicolumn{6}{|l|}{ Men } \\
\hline Age & 1 & $1.21(0.93,1.56)$ & $1.43(1.10,1.86)$ & $1.36(1.05,1.78)$ & $1.50(1.12,2.00)$ \\
\hline+ SES & 1 & $1.10(0.84,1.43)$ & $1.34(1.02,1.74)$ & $1.23(0.94,1.61)$ & $1.34(1.00,1.80)$ \\
\hline + Education & 1 & $1.05(0.81,1.37)$ & $1.24(0.95,1.61)$ & $1.16(0.88,1.52)$ & $1.27(0.95,1.71)$ \\
\hline + Employment status & 1 & $1.17(0.90,1.52)$ & $1.41(1.08,1.83)$ & $1.31(1.00,1.71)$ & $1.44(1.08,1.93)$ \\
\hline + Marital status & 1 & $1.22(0.94,1.59)$ & $1.44(1.11,1.87)$ & $1.38(1.06,1.79)$ & $1.54(1.15,2.06)$ \\
\hline + Ethnicity & 1 & $1.20(0.93,1.56)$ & $1.42(1.09,1.84)$ & $1.35(1.04,1.76)$ & $1.46(1.10,1.96)$ \\
\hline+ All & 1 & $0.98(0.75,1.29)$ & $1.18(0.90,1.56)$ & $1.08(0.82,1.42)$ & $1.19(0.88,1.62)$ \\
\hline \multicolumn{6}{|l|}{ Women } \\
\hline Age & 1 & $1.67(1.13,2.49)$ & $1.92(1.29,2.87)$ & $2.15(1.44,3.21)$ & $1.94(1.22,3.09)$ \\
\hline+ SES & 1 & $1.66(1.10,2.50)$ & $1.77(1.16,2.70)$ & $2.04(1.34,3.11)$ & $1.75(1.07,2.85)$ \\
\hline + Education & 1 & $1.52(1.01,2.27)$ & $1.73(1.15,2.61)$ & $1.88(1.25,2.84)$ & $1.62(1.01,2.06)$ \\
\hline + Employment status & 1 & $1.71(1.14,2.55)$ & $1.94(1.29,2.92)$ & $2.12(1.41,3.18)$ & $1.94(1.21,3.11)$ \\
\hline + Marital status & 1 & $1.65(1.11,2.46)$ & $1.91(1.28,2.86)$ & $2.17(1.45,3.25)$ & $1.92(1.20,3.05)$ \\
\hline + Ethnicity & 1 & $1.68(1.13,2.49)$ & $1.89(1.26,2.82)$ & $2.14(1.43,3.19)$ & $1.93(1.21,3.06)$ \\
\hline+ All & 1 & $1.57(1.02,2.40)$ & $1.68(1.08,2.60)$ & $1.91(1.24,2.96)$ & $1.60(0.96,2.66)$ \\
\hline
\end{tabular}

- The first factor defines Swedish working class areas with low mobility, whose young adults have difficulties entering the labour market (the class structure index).

- The second factor defines areas with high turnover and exclusion from family and labour market foremost among middle aged and elderly (the social exclusion index).

- The third factor defines ethnically heterogeneous areas with a high extent of public housing, high levels of welfare recipients and a high rate of lone parents (the poverty index).

\section{Contextual effects}

The result from the multilevel models with just a random intercept resulted in an intraclass correlation for men of $0.8 \%$. When introducing variables of the contextual exposure the variance at the second level disappeared.

The intraclass correlation for women was $6.7 \%$. After introducing the second level variable (contextual exposure), the intraclass correlation decreased to $3.6 \%$ and disappeared when including age in the model. Given this, we only report results from single level models in the tables. ${ }^{41}$

\section{Class structure index}

Men exposed to a social context defined by levels of the class structure index found in the most deprived quintile of parishes, had a relative risk of myocardial infarction of 1.50 $(95 \%$ CI $1.12,2.00)$ compared with men living in the least deprived quintile of areas (table 3 ). However, individual socioeconomic status largely explained the effect of this dimension. The relative risk was reduced to $1.27(0.95,1.71)$ when adjusting for education and to $1.19(0.88,1.62)$ in the full model.

The result for women had a different pattern. There was an increased relative risk in all quintiles except the referent quintile. If these four quintiles were merged the crude relative risk of myocardial infarction was $1.91 \quad(1.36,2.68)$ and after adjustment for all individual covariates the risk decreased to $1.69(1.17,2.44)$ (not shown in table).

\section{Social exclusion index}

The relative risk of myocardial infarction was 1.39 (95\% CI 1.04, 1.84) among men living in the most deprived quintile according to the social exclusion index relative to men living in the least deprived quintile (table 4). A threshold occurs between the less deprived areas in the 1st and 2nd quintile

Table 4 Relative risks (95\% confidence intervals) of myocardial infarction by exposure quintile for the social exclusion index

\begin{tabular}{|c|c|c|c|c|c|}
\hline \multirow[b]{2}{*}{ Model } & \multicolumn{5}{|c|}{ Exposure quintile } \\
\hline & 1 & 2 & 3 & 4 & 5 \\
\hline \multicolumn{6}{|l|}{ Men } \\
\hline Age & 1 & $1.07(0.81,1.41)$ & $1.32(1.01,1.72)$ & $1.33(1.04,1.71)$ & $1.39(1.04,1.84)$ \\
\hline+ SES & 1 & $1.06(0.80,1.40)$ & $1.26(0.96,1.65)$ & $1.27(0.98,1.63)$ & $1.37(1.03,1.83)$ \\
\hline + Education & 1 & $1.03(0.78,1.36)$ & $1.26(0.96,1.64)$ & $1.25(0.97,1.60)$ & $1.39(1.04,1.85)$ \\
\hline + Employment status & 1 & $1.04(0.79,1.38)$ & $1.30(0.99,1.70)$ & $1.30(1.02,1.67)$ & $1.38(1.04,1.84)$ \\
\hline + Marital status & 1 & $1.07(0.81,1.41)$ & $1.31(1.00,1.71)$ & $1.30(1.01,1.66)$ & $1.29(0.96,1.72)$ \\
\hline + Ethnicity & 1 & $1.07(0.81,1.42)$ & $1.30(1.00,1.70)$ & $1.32(1.04,1.69)$ & $1.40(1.05,1.86)$ \\
\hline+ All & 1 & $1.04(0.78,1.39)$ & $1.22(0.93,1.61)$ & $1.19(0.92,1.54)$ & $1.34(1.00,1.81)$ \\
\hline \multicolumn{6}{|l|}{ Women } \\
\hline Age & 1 & $1.71(1.09,2.69)$ & $1.28(0.85,1.93)$ & $2.16(1.48,3.16)$ & $1.38(0.90,2.13)$ \\
\hline+ SES & 1 & $1.73(1.06,2.82)$ & $1.33(0.86,2.05)$ & $2.36(1.57,3.54)$ & $1.56(0.98,2.46)$ \\
\hline + Education & 1 & $1.66(1.05,2.62)$ & $1.21(0.80,1.83)$ & $2.02(1.38,2.97)$ & $1.38(0.89,2.14)$ \\
\hline + Employment status & 1 & $1.64(1.04,2.61)$ & $1.25(0.82,1.91)$ & $2.10(1.42,3.09)$ & $1.40(0.90,2.17)$ \\
\hline + Marital status & 1 & $1.68(1.07,2.65)$ & $1.27(0.84,1.92)$ & $2.09(1.43,3.06)$ & $1.32(0.86,2.03)$ \\
\hline + Ethnicity & 1 & $1.72(1.09,2.70)$ & $1.28(0.85,1.94)$ & $2.18(1.49,3.18)$ & $1.41(0.92,2.17)$ \\
\hline+ All & 1 & $1.56(0.94,2.56)$ & $1.22(0.78,1.90)$ & $2.08(1.37,3.16)$ & $1.45(0.90,2.32)$ \\
\hline
\end{tabular}


and the more deprived areas in the 3rd, 4th and 5th quintile. Comparing men living in the three more deprived quintiles with men living in the two less deprived, results in a crude relative risks of myocardial infarction of 1.30 (1.10, 1.54), and after adjustment for all individual covariates the relative risks decreased to 1.21 (1.01, 1.45) (not shown in table). There were also increased effect estimates among women, but as they were largest in quintile two and four it indicates that this contextual measure does not measure a contextual feature of importance for women.

\section{Poverty index}

Men living in the most deprived quintile according to the poverty index had a relative risk of myocardial infarction of 1.31 $(95 \%$ CI $0.98,1.74)$ relative to men living in the least deprived area quintile (table 5). In accordance with the effect of the social exclusion dimension, a threshold pattern occurs between quintile 2 and 3. Comparing men living in the more deprived areas with men living in the less deprived, results in a crude relative risk of 1.33 (95\% CI $1.11,1.59)$ and after adjustment the relative risk decreases to 1.27 (1.05, 1.53). The effect estimates among women were low in all quintiles.

\section{DISCUSSION}

The result of this study indicates that the socioeconomic context of areas influences risk of myocardial infarction, and that corresponding individual social characteristics only partly explains the association.

The strongest effect among men was between the 2 nd and the 3rd quintile while the most deprived quintiles showed no further excess risk. The poverty dimension had the strongest contextual impact on the relative risk of myocardial infarction. Only $21 \%$ of its excess risk were explained by social factors on the individual level. The class structure dimension had the strongest crude effect but the social factors on the individual level explained $43 \%$ of the excess risk.

Among women, the class structure dimension had the strongest impact. In comparison with women living in upper class areas (with high prevalence of high income earners and low levels of unemployment among young adults), women in the rest of Stockholm metropolitan area had nearly $70 \%$ higher risk of myocardial infarction after adjustment for individual social class. The stronger relative risk among women than among men, might be a product of the lower incidence among women. ${ }^{36}$

The magnitude of the variance between parishes in the hierarchical regression analysis was rather small, which is in accordance with earlier findings, ${ }^{41}$ but we still capture important exposure contrasts when grouping the parishes according to the

\section{Key points}

- The socioeconomic context in area of living affects the relative risk of first event of myocardial infarction, despite Sweden's relatively narrow exposure contrast.

- The effect of socioeconomic context differs between sexes, which encourage separate analysis and further evaluation of gender specific contextual features.

- There are several dimensions of socioeconomic context and the contextual effect of these dimensions is to a varying extent explained by the corresponding individual characteristics.

factor analysis. In other words, although parishes are somewhat homogeneous with respect to the outcome (particularly for men), grouping them according to their socioeconomic characters reveals heterogeneity between the groups.

The contrasts in contextual exposures between different parishes in the Stockholm metropolitan region (see table 1) are probably small in an international perspective attributable to the history of compensatory mechanisms, although the comparisons with other populations are difficult as the same indicators describing areas of compatible sizes are rarely available. The differences in living conditions between different parishes of Stockholm have, however, been described as a serious health inequality issue in health and social policy documents. ${ }^{42}$

Despite the problem of comparability between exposures, the sizes of the effect estimates in different studies are very similar. Waizman and Smith studied poverty area residence and mortality in the United States and report a relative risk of cardiovascular mortality of $1.88(1.23,2.88)$ after adjustment for individual and household characteristics among nonelderly adults. The contextual exposure was determined by living in federally designated poverty areas. ${ }^{13}$ Yen and Kaplan used a factor analysis of area characteristics to estimate social context of the local neighbourhood in the Alameda county study. They reported crude relative risks of mortality of 1.40 to 1.58, and each component of the context was associated with a higher risk for mortality after adjustment of individual social and health factors. Though the indicators differed and consequently also the factors, they showed, in similarity with our results, that population SES (comparable with our class structure dimension) was largely explained by individual income. They also found that the relative risk increased among low income earners in areas with higher population SES. ${ }^{21}$ In a study from Renfrew and Paisley in Scotland, Davey Smith and

Table 5 Relative risks (95\% confidence intervals) of myocardial infarction by exposure quintile for the poverty index

\begin{tabular}{|c|c|c|c|c|c|}
\hline \multirow[b]{2}{*}{ Model } & \multicolumn{5}{|c|}{ Exposure quintile } \\
\hline & 1 & 2 & 3 & 4 & 5 \\
\hline \multicolumn{6}{|l|}{ Men } \\
\hline Age & 1 & $0.88(0.64,1.20)$ & $1.18(0.86,1.62)$ & $1.16(0.87,1.56)$ & $1.31(0.98,1.74)$ \\
\hline+ SES & 1 & $0.91(0.66,1.26)$ & $1.21(0.88,1.67)$ & $1.14(0.85,1.53)$ & $1.28(0.96,1.71)$ \\
\hline + Education & 1 & $0.95(0.69,1.30)$ & $1.25(0.91,1.72)$ & $1.20(0.90,1.61)$ & $1.31(0.98,1.75)$ \\
\hline + Employment status & 1 & $0.87(0.63,1.19)$ & $1.18(0.86,1.63)$ & $1.15(0.86,1.54)$ & $1.30(0.97,1.73)$ \\
\hline + Marital status & 1 & $0.87(0.64,1.20)$ & $1.16(0.84,1.59)$ & $1.15(0.86,1.54)$ & $1.29(0.97,1.72)$ \\
\hline + Ethnicity & 1 & $0.88(0.64,1.21)$ & $1.19(0.86,1.63)$ & $1.16(0.87,1.56)$ & $1.30(0.98,1.73)$ \\
\hline+ All & 1 & $0.97(0.70,1.34)$ & $1.28(0.93,1.78)$ & $1.17(0.87,1.58)$ & $1.28(0.95,1.72)$ \\
\hline \multicolumn{6}{|l|}{ Women } \\
\hline Age & 1 & $0.73(0.44,1.20)$ & $1.18(0.71,1.96)$ & $1.03(0.65,1.64)$ & $1.23(0.77,1.96)$ \\
\hline+ SES & 1 & $0.80(0.47,1.37)$ & $1.22(0.70,2.12)$ & $1.08(0.66,1.78)$ & $1.36(0.83,2.25)$ \\
\hline + Education & 1 & $0.86(0.52,1.44)$ & $1.28(0.77,2.14)$ & $1.10(0.69,1.75)$ & $1.30(0.81,2.07)$ \\
\hline + Employment status & 1 & $0.70(0.42,1.16)$ & $1.14(0.68,1.93)$ & $0.99(0.62,1.60)$ & $1.17(0.73,1.89)$ \\
\hline + Marital status & 1 & $0.70(0.42,1.16)$ & $1.14(0.68,1.91)$ & $0.99(0.62,1.58)$ & $1.21(0.76,1.93)$ \\
\hline + Ethnicity & 1 & $0.74(0.45,1.21)$ & $1.19(0.71,1.98)$ & $1.04(0.65,1.659$ & $1.24(0.78,1.99)$ \\
\hline+ All & 1 & $0.81(0.46,1.41)$ & $1.18(0.67,2.08)$ & $1.03(0.62,1.72)$ & $1.30(0.78,2.17)$ \\
\hline
\end{tabular}


colleagues reported a relative risk of 1.26 for cardiovascular mortality and 1.34 for total mortality among men after adjustment for occupation based social class. Among women the corresponding relative risks were 1.33 and $1.29 .{ }^{12}$ Malmström et al did a national follow up study on total mortality in Sweden and found a relative risk of total mortality of 1.50 to 1.68 in deprived areas, after adjustment for occupation based SES. They used a modified version of Jarman UPA index (Care Need Index) to measure area deprivation. ${ }^{22}$

Comparisons of contextual effects are problematic. The wide variety of geographical levels, exposure measures and outcomes diminish the amount of comparable studies. Studies on cardiovascular mortality ${ }^{32}{ }^{13}$ and especially cardiovascular morbidity ${ }^{714}$ are uncommon. Contextual exposures might be expected to have stronger effects on mortality compared to incidence of disease as case fatality rates could be related to deprivation levels. Furthermore, the risk of bias from health selection is more pronounced in both mortality studies and studies with prevalent outcomes. Therefore incident first events of the disease are the preferable outcome if the research question concerns disease aetiology.

Some causal mechanisms exploring the association of social context in place of living and coronary heart disease have been suggested. It has, for example been proposed that people living in areas suffering from disinvestment in human, health and social infrastructure and lack of materialistic resources will experience an accumulation of negative exposures and experiences that will effect their health negatively. ${ }^{25} 29$ LeClere et al conducted a multilevel analysis to study mechanisms behind racial differences in women's heart disease mortality in US. They found an $85 \%$ excess risk for younger, and a $23 \%$ excess risk for older women who lived in communities where more than a quarter of the families were headed by women, after adjustment for individual risk factors and socioeconomic characteristics including individual marital status. This contextual exposure together with individual SES accounted for the racial differences in the women's heart disease mortality. They suggest that these areas create stressful social obligations and lack social resources, which contribute to increase financial, physical and emotional stress both for the women and for the communities in general. ${ }^{14}$

People's health behaviour is also influenced by the context, which could be considered as an indirect contextual effect or a mediating mechanism. Several studies report higher frequencies of negative health related behaviour in deprived areas ${ }^{61119}$ and that residence in a poverty area leads to decreased physical activity ${ }^{18}$ and influences preferences concerning health related behaviours especially during adolescence. ${ }^{5}$ Diez-Roux and colleagues reported that residence in deprived neighbourhoods is associated with increased prevalence of coronary heart disease and increased levels of risk factors like smoking, systolic blood pressure and serum cholesterol that generally persist after adjustment for individual factors. ${ }^{7}$

\section{Methodological considerations}

Area of living or local neighbourhood is the close surroundings with natural borders where the inhabitants make regular social exchanges with individuals and with institutions. This would be the most relevant geographical level in these types of studies. ${ }^{44}{ }^{45}$ Parishes may have been the best choice when the church was the most important institution, but today the important areas may be smaller and have other borders. Hence, parishes could be heterogeneous with regard to neighbourhood characteristics, which would result in non-differential misclassification biasing the relative risk towards unity.

These analyses assume that the measured exposure of neighbourhood context one year before inclusion affects risk of myocardial infarction and the length of residence or residential mobility are not considered. This could lead to a misclassification bias that would also dilute the effect.
However, $76 \%$ of the referents in the study have lived at the same address for 10 years or more. It has also been shown in other populations that when people move, they tend to move to similar areas, rather than better or worse. ${ }^{46}$

It is possible that we have a misclassification of socioeconomic status on the individual level, as we use a variable based on each individual own occupation and lack data of the household socioeconomic position. This could imply residual confounding from social circumstances on the individual level, especially among women.

The problem of residual confounding from individual level risk factors is considerable in these types of studies. ${ }^{47-49}$ This study, as many of the other studies mentioned here, controls for social position. We also control for many of the socioeconomical factors on the individual level that operate in the segregation process ${ }^{42}$ to distinguish the contextual effect from the compositional. However, because of lack of information it has not been possible to control for all individual characteristics used in the construction of the contextual exposure measures. Finally there are a number of potential confounders that we would prefer to regard as downstream mediating factors in the contextual mechanism. We have however also adjusted for behavioural factors as smoking, physical activity and obesity. When we controlled for smoking it only had a minor influence on the effect estimates among men. With the dichotomous exposure categories the relative risk among men living in areas exposed to the class structure dimension decreased from 1.16 to 1.15 when including smoking in the full model, and among men living in areas exposed to the poverty dimension the relative risk increased from 1.26 to 1.27. Among women the relative risk decreased from 1.69 to 1.55 for the dichotomised version of the class structure dimension when including smoking in the full model. A few others such as job strain are partly adjusted for by adjusting SES, but further inclusion of such exposure does not change the contextual effect.

The health selection is usually a problem when analysing the causal relation between area of living and health, especially when analysing contextual effects on chronicle diseases. ${ }^{50}$ The use of incident first event of myocardial infarction as outcome makes this study less sensitive to this kind of bias than studies with prevalent outcome. To further prevent the health selection bias we controlled for confounding from employment status, including categories of long term illness and early retirement.

In conclusion, the results suggest that the socioeconomic context in area of living increase the risk of myocardial infarction. This contextual effect is only partly explained by individual social factors and the effect pattern differs between men and women.

\section{ACKNOWLEDGEMENTS}

The SHEEP Study Group: Karolinska Institute: Institute of Environmental Medicine, Department of Public Health Sciences, Units of Social Medicine and Occupational Health, and Department of Medical Epidemiology; National Institute for Working Life, Department of Occupational Health; National Institute for Psychosocial Factors and Health; Stockholm County Council: Departments of Environmental Medicine, Epidemiology, Occupational Health, and Social Medicine; the Departments of Medicine at Danderyd, Huddinge, Löwenströmska, Nacka, Norrtälje, Sabbatsberg, St Görans, Södersjukhuset, and Södertälje Hospital, and the Departments of Cardiovascular Medicine and Clinical Chemistry, Karolinska Hospital (all at hospitals in the County of Stockholm, Sweden).

We would like to thank Antonio Ponce de Leon and Tomas Andersson for valuable statistical advice and for help with some of the statistical analysis.

Funding: the Swedish Council for Social research.

Conflicts of interest: none. 


\section{Authors' affiliations}

M Kölegård Stjärne, F Diderichsen, J Hallqvist, Division of Social Medicine, Department of Public Health Sciences, Karolinska Institutet, Stockholm, Sweden

C Reuterwall, Division of Epidemiology, Institute of Environmental Medicine, Stockholm County Council, Stockholm, Sweden

\section{REFERENCES}

1 Anderson RT, Sorlie P, Backlund E, et al. Mortality effects of community socio-economic status. Epidemiology 1996;8:42-7.

2 Kaplan GA. People and places: contrasting perspectives on the association between social class and health. International Journal of Health Services 1996;26:507-19.

3 Davey Smith G, Neaton JD, Wentworth D, et al. Socioeconomic differentials in mortality risk amoung men screened for the multiple risk factor intervention: I. White men. A J Public Health 1996:86:486-96.

4 Shouls S, Congdon P, Curtis S. Modeling inequality in reported long term illness in the UK: combining individual and area characteristics. $J$ Epidemiol Community Health 1996;50:366-76.

5 Karvonen S, Rimpelä A. Socio-regional context as a determinant of adolescents' health behaviour in Finland. Soc Sci Med 1996:43: 1467-74

6 Ellaway A, Macintyre S. Does where you live predict health related behaviours? Health Bull 1996;54:443-6.

7 Diez-Roux AV, Nieto JF, Muntaner C, et al. Neighbourhood and coronary heart disease: a multilevel analysis. Am J Epidemiol 1997; 146:48-63.

8 Hart C, Ecob R, Davey Smith G. People places and coronary heart disease risk factors: a multilevel analysis of the Scottish heart health study archive. Soc Sci Med 1997;45:893-902.

9 Reijneveld SA, Schene AH. Higher prevalence of mental disorders in socioeconomically deprived urban areas in the Netherlands: community or personal disadvantage? J Epidemiol Community Health 1997;52:2-7.

10 Karvonen S, Rimpelä AH. Urban small area variation in adolescents health behaviour. Soc Sci Med 1997;45: 1089-98.

11 Ellaway A, Anderson A, Macintyre S. Does area of residence affect body size and shape? Int J Obes 1997;21:304-8.

12 Davey Smith G, Hart C, Watt G, et al. Individual social class, area-based deprivation, cardiovascular disease risk factors, and mortality: the Renfrew and Paisley study. J Epidemiol Community Health 1998:52:399-405

13 Waitzman JN, Smith KR. Phantom of the area: poverty-area residence and mortality in the United States. Am J Public Health 1998;88:973-6.

14 LeClere FB, Rogers RG, Peters K. Neighbourhood social context and racial differences in women's heart disease mortality. J Health Soc Behav 1998;39:91-107.

15 Waitzman JN, Smith KR. Separate but lethal: the effects of economic segregation on mortality in metropolitan America. Milbank $Q$ 1998; 78:341-73.

16 Robert SA. Community-level socioeconomic status effects on adult health. J Health Soc Behav 1998;39: 18-37.

17 Reijneveld SA. The impact of individual and area characteristics on urban socioeconomic differences in health and smoking. Int J Epidemiol 1998;27:33-40

18 Yen IH, Kaplan GA. Poverty area residence and changes in physical activity level: evidence from the Alameda county study. Am J Public Health 1998:88:1709-12.

19 Sundquist J, Malmström M, Johansson S-E. Cardiovascular risk factors and the neighbourhood environment: a multilevel analysis. Int J Epidemiol 1999;28:841-5

20 Yen IH, Kaplan GA. Poverty area residence and changes in depression and precived health status: evidence from the Alameda county study. Int $J$ Epidemiol 1999;28:90-4

21 Yen IH, Kaplan GA. Neighborhood social environment and risk of death: multilevel evidennce from the Alameda county study. Am J Epidemiol 1999;149:898-907.

22 Malmström M, Johansson S-E, Sundquist J. A hierarchical analysis of long-term illness and mortality in socially deprived areas. Soc Sci Med $2001 ; 53: 265-75$.
23 Haan M, Kaplan GA, Camacho T. Poverty and health: prospective evidence from the Alameda county study. Am J Epidemiol 1987; 125:989-98.

24 Wilkinson RG. Income distribution and life expectancy. BM 1992;304:165-8.

25 Kaplan GA, Pamuk ER, Lynch JW, et al. Inequality in income and mortality in the United States: analysis of mortality and potential pathways. BN 1996;312:999-1003.

26 Kennedy BP, Kawachi I, Prothrow-Stith D. Income distribution and mortality: cross sectional ecological study of the Robin Hood index in the United States. BM 1996;312:1004-7.

27 Lynch JW, Kaplan GA, Pamuk ER, et al. Income inequality and mortality in metropolitan areas of the United States. Am J Publ Health 1998;88:1074-80.

28 Wilkinson R. Unhealthy societies. The afflictions of inequality. London: Routledge, 1996

29 Lynch JW, Davey Smith G, Kaplan GA, et al. Income inequality and mortality: importance to health of individual income, psychosocial environment, or material conditions. BM 2000;320:1200-4.

30 Carstairs V. Deprivation indices: their interpretation and use in relation to health. J Epidemiol Community Health. 1995;49:s3-8.

31 Drever $\mathbf{F}$, Whitehead $M$. Mortality in regions and local authority districts in the 1990. Exploring the relationship with deprivation. Population Trends 1995;82:19-26.

32 Jarman. Underprivileged areas: validation and distribution of scores. BM 1984;289:1587-92.

33 Diderichsen F, Varde E, Whitehead M. Resource allocation to health authorities: the quest for an equitable formula in Britain and Sweden. BM 1997;315:875-8.

34 Malmström M, Sundquist J, Bajekal $M$, et al. Indices of need and social deprivation for primary health care. Scand J Soc Med 1998;26:124-30.

35 Andersson P-Á, Varde E, Diderichsen F. Modelling of resource allocation to health authorities in Stockholm County. Health Care Management Science 2000;3:141-9.

36 Reuterwall C, Hallqvist J, Ahlbom A, et al. Higher relative but lower absolute risks of myocardial infarction in women than in men for some major risk factors in the SHEEP study. J Intern Med 1999;246:161-74

37 Hallqvist J. Socioeconomic differences in myocardial infarction risk. Epidemiological analyses of causes and mechanisms. [Dissertation.] Stockholm: Karolinska Institutet, 1998

38 Hiärtintensivvård. Stockholms läns landsting. [In Swedish]. Stockholm: Stockholm County Council, 1990

39 Statistics Sweden (1982). Swedish socioeconomic classification. Stockholm: Reports on statistical co-ordination, 1982:4

$40 \mathrm{Kim} \mathrm{J-O,} \mathrm{Mueller} \mathrm{CW.} \mathrm{Factor} \mathrm{analysis} \mathrm{statistical} \mathrm{methods} \mathrm{and} \mathrm{practical}$ issues. California: Sage, 1989

41 Diez-Roux AV. Multilevel analysis in public health research. Annu Rev Public Health 2000;21:171-92.

42 Storstadskommitténs betänkande. Tre Städer. [In Swedish] Stockholm: Fritzes, SOU, 1998:25.

43 Blane D, Bartley M, Davey Smith G. Disease aetiology and materialist explanations of socioeconomic mortality differentials. Eur J Public Health 1997;7:385-91.

44 Macintyre S, Maciver S, Sooman A. Area, class and health: Should we be focusing on places or people? Journal of Social Policy 1993;22:213-34.

45 Reijneveld SA, Verheij RA, de Bakker D. The impact of area deprivation on differences in health: does the choice of the geographical classification matter? J Epidemiol Community Health 2000;54:306-13.

46 Haan MN, Kaplan GA Syme SL, O'Neil A. Socioeconomic status and health: old observations and new thoughts. In: Bunker JP, Gomby DS, Keher HB. Pathways to health: the role of social factors. Menlo Park, CA Henry J Kaiser family foundation, 1989:76-135.

47 Kaufman JS, Cooper RS, McGee DL. Socioeconomic status and health in blacks and whites: the problem of residual confounding and the resiliency of race. Epidemiology 1997;8:621-8.

48 Diez-Roux AV. Bringing context back into epidemiology: variables and fallacies in multilevel analysis. Am J Public Health 1998;88:216-22.

49 Blakely T. Woodward A. Ecological effects in multi-level studies. J Epidemiol Community Health 2000;54:367-74.

50 Diderichsen F. Omflyttning Boende och Hälsa. [Dissertation.] Uppsala: Uppsala Universitet, 1981 